\title{
Contraceptive use, prevalence and predictors of pregnancy planning among female sex workers in Uganda: a cross sectional study
}

Justine Nnakate Bukenya ${ }^{1 *}$ (D) Rhoda K. Wanyenze ${ }^{1}$, Geraldine Barrett ${ }^{2}$, Jennifer Hall ${ }^{2}$, Fredrick Makumbi ${ }^{1}$ and David Guwatudde ${ }^{1}$

\begin{abstract}
Background: Unintended pregnancies are associated with negative consequences to both mother and baby. Female Sex Workers (FSWs) are at high risk of unintended/unplanned pregnancies. However, prevalence of pregnancy planning and its predictors among FSWs has not been comprehensively investigated. This study was designed to determine contraceptive use, the prevalence, and predictors of pregnancy planning among FSWs in Uganda.
\end{abstract}

Methods: In this cross-sectional study, 819 FSWs attending most at risk populations initiative (MARPI) clinics were recruited using systematic sampling and interviewed with a pretested questionnaire that included collection of data on pregnancy intention using the London Measure of Unplanned Pregnancy (LMUP). Data were analysed using STATA version 14.0. Multinomial logistic regression model was used to identify predictors of pregnancy planning,

Results: Of the 819 study participants, only 90 (11.0\%) had planned pregnancies. Overall, 462 (56.4\%) were hazardous alcohol users and 335 (40.9\%) abused drugs; 172 (21.0\%) had been raped in the last 2 years and $70(40.7 \%)$ of these accessed emergency contraception post-rape. Dual contraception use (condom and other modern method) was 58.0\%.

Having a non-emotional partner as a man who impregnated the FSW compared to emotional partner was significantly associated with less planned relative to unplanned pregnancy, $(a R R=0.1595 \% \mathrm{Cl}=0.08,0.30)$, so was lack of reported social support compared to support from friends, (aRR $=0.44 ; 95 \% \mathrm{Cl}=0.22-0.87$ ), keeping all factors constant in the model. Being raped ( $\mathrm{aRR}=0.51 ; 95 \% \mathrm{Cl}=0.31-0.84$ ) or abuse of substances (aRR $=0.65 ; 95 \% \mathrm{Cl}=0.45-0.93)$ were significantly associated with lower ambivalence relative to unplanned pregnancy but not with planned relative to unplanned pregnancy.

Conclusion: Compared to women in the general population, pregnancy planning was low among FSWs amidst modest use of dual contraceptive. There is an urgent need to promote dual contraception among FSWs to prevent unplanned pregnancies especially with non-emotional partners, drug users, and post-rape.

Keywords: Female sex workers, Pregnancy planning, Predictors, Uganda, Low income countries

\footnotetext{
* Correspondence: jbukenya@musph.ac.ug

${ }^{1}$ School of Public Health, College of Health Sciences Makerere University, P.O.

Box 7072, Kampala, Uganda

Full list of author information is available at the end of the article
}

(c) The Author(s). 2019 Open Access This article is distributed under the terms of the Creative Commons Attribution 4.0 International License (http://creativecommons.org/licenses/by/4.0/), which permits unrestricted use, distribution, and reproduction in any medium, provided you give appropriate credit to the original author(s) and the source, provide a link to the Creative Commons license, and indicate if changes were made. The Creative Commons Public Domain Dedication waiver (http://creativecommons.org/publicdomain/zero/1.0/) applies to the data made available in this article, unless otherwise stated. 


\section{Background}

Pregnancy planning is an important public health practice that should be promoted among women of reproductive age. Pregnancy planning involves, to a greater or lesser extent, the conscious choice to become pregnant and is a necessary component in the adoption of healthier lifestyles before conception that are associated with positive maternal and child outcomes [1]. On the contrary, unplanned pregnancies are associated with poor economic, social, and health consequences. Such negative outcomes include low-birth weight and increased risk of infant mortality [2], and among women abortion-related mortalities [3] and financial expenses while procuring abortion and care $[4,5]$. Planning pregnancies provides an opportunity to harness the biomedical, behavioural and social health interventions to improve the health status of women in preparation for safe conception [6]. This contributes to better maternal and child health outcomes.

Though there is a challenge in estimating the actual number of Female Sex Workers (FSWs) globally, available data indicate that in sub Saharan Africa about 0.7$4.3 \%$ of women exchange sex for money or goods [7]. In Uganda, 3.3\% of women aged 15 and above were estimated to be FSWs in the capital city of Kampala [8]. Due to the criminalized nature of sex work in Uganda [9] these figures could be underestimates. Furthermore, criminalization drives most sex work to happen within an unhealthy and unregulated working environment. In Uganda, sex workers operate within their residence, often located in the various slum areas of trading centres, in entertainment places and along busy roadsides in some parts of the country, while others get clients through phone calls. [10].

In sub-Saharan Africa, unplanned pregnancies among female sex workers are common, ranging from $28.6 \%$ in Ethiopia [11] to $69.0 \%$ in Côte d'Ivoire [12]. Factors associated with unplanned pregnancy among FSWs include having four or more children, being unmarried, being adolescents or being older than 30 years, and use of drugs and alcohol $[11,13]$. Other factors that have been associated with pregnancy planning among women in the general population include family support for becoming pregnant, residing in urban setting, and number of previous pregnancies [14].

Use of contraceptives by FSWs has been modest according to previous studies in Uganda [15]. Many times FSWs use unreliable methods such as natural methods while others use condoms inconsistently [16]. FSWs have high unmet need for sexual and reproductive health services including contraceptives due to accessibility difficulties [15]. The Ministry of Health in Uganda developed guidelines to ensure provision of integrated health services including family planning services among most at risk populations [17] but little is known about the extent to which FSWs have used contraceptives.

Pregnancy planning is a complex construct [18] and has been assessed using various ways. Most tools used in assessment assume that women already have an established choice about getting pregnant [19] yet many women are ambivalent. The London Measure of Unplanned Pregnancy (LMUP) [20], which is a psychometric measure of pregnancy planning and allows women to express a variety of positions in relation to the concept, has been used to measure pregnancy intendedness in the general population globally but has not been used among FSWs, a population at high risk of unintended pregnancies. Further, there is limited information on the extent of pregnancy planning among FSWs especially in Uganda. This study investigated contraceptive use and prevalence and predictors of pregnancy planning among FSWs in Uganda using the validated Ugandan LMUP.

\section{Methods \\ Study design and site}

A cross-sectional study design was used. Participants were recruited from four hospitals where clinics for the 'most at risk populations initiative' (MARPI), including FSWs, have been established, in the four regions of Uganda including Central, Northern, Western and Eastern. The MARPI clinic in central region was established in 2008 while the other three clinics were established in 2015. The MARPI clinics offer free reproductive health services including Human Immunodeficiency Virus (HIV) testing, prevention, treatment, care, support and management of other sexually transmitted infections; cancer screening, and family planning services [21]. The clinics do not provide maternal health care services.

\section{Sample size}

A sample size of 379 women was calculated using the formula for single population cross-sectional studies [22], and assuming a prevalence of unplanned pregnancy of $44 \%$, a $5 \%$ level of significance, and an error of 0.05 . The estimated prevalence of unplanned pregnancy estimate of $44 \%$ was obtained from a study conducted among FSWs in 2012 in Gulu district in Uganda [15]. The calculated sample size was adjusted with a design effect of 2.0 to compensate for inter-cluster variation to obtain a sample size of 758 . This was further adjusted for an anticipated non-response rate of $5 \%$ on any study variables [23], to obtain a final sample size of 800 participants. However data was collected among 819 FSWs due to concurrent enrolment across sites.

\section{Sampling procedure}

The calculated sample size was allocated to the four MARPI clinics in proportion to their registered FSWs 
clientele. The FSWs recruited from central, Eastern, Western and Northern MARPI clinics were 517, 90, 112, and 100 respectively. FSWs were eligible for inclusion into the study if they were aged between 15 and 49 years and had been pregnant within the 2 years preceding the date of interview for this study. In addition, FSWs who could not consent because of illness or intoxication with alcohol and/or drugs at the time of screening were excluded.

MARPI Clinic in the central region receives about 2030 FSWs per day whereas the other three sites receive 8-15 FSWs per day. We planned to enrol 6 FSWs from MARPI Clinic in the central region and 2 from the other three MARPI clinics per day over a period of 4 months. To enrol the required number of FSWs over the 4 months' period, systematic sampling was used where every third FSW registering at the reception at MARPI Clinic in the central region and every second FSW in the other MARPI clinics were approached by research assistants. They introduced the study and obtained written informed consent to administer the screening tool. After screening, written informed consent was sought from eligible FSWs. The study was conducted between May and August 2017.

\section{Study tool development and pre-testing}

We used the LMUP tool [20] which has been psychometrically validated in general populations in both low and high income countries [13, 19, 24-26]. The LMUP tool was reviewed and other variables found in literature to be associated with pregnancy planning were added to develop the questionnaire. The LMUP was translated into the local languages of Luganda, Acholi, Lugisu, and Runyankole and was then validated among FSWs. The revised questionnaire was further pre-tested among FSWs who had not sought services from any MARPI clinics in the district of Mukono, east of Kampala District. During pre-testing, we checked for the understanding of the various questions by FSWs and made the necessary revisions in the wording. The final pre-tested questionnaire was used to collect data by experienced research assistants who had been trained for 3 days before data collection.

\section{Measurements}

The LMUP comprises six questions capturing information on a woman's circumstances during the most recent pregnancy with respect to use of contraceptives, timing of pregnancy, pregnancy intention, wanting to have a baby, discussion with the man who fathered the last pregnancy, and preconception preparation. Each question was scored on $0-2$ scale, with a total score of $0-12$ [20]. Each point increase represents an increase in pregnancy planning effort.

Data were collected on a) Socio-demographic and economic characteristics We included age, marital status, and education. We also collected data on economic indicators including household properties such as ownership of a radio, television, bicycle, motorcycle, home ownership, cell phone, regular phone, computer, an income generating activity, an indoor bathroom, water source, electricity, car, generator, and solar power source.

b) Sexual and obstetric history

These included the number of living biological children, duration of working as a FSW and main place of recruiting clients. The main work place was defined as the venue for recruiting clients including streets, entertainment places, residence as well as use of phone. FSWs were also asked if they had ever tested for HIV and the most recent result. Where available, clinic records were used to classify the HIV status of each FSW. Clinic records were used in preference to the self-reported status by the FSW. In case records were missing, HIV status was categorised as unverified. Data were collected on partner type including emotional and non-emotional client (either regular or occasional clients). An emotional partner was defined as a man with whom a FSW felt an emotional attachment after a sexual encounter even if he did not give money or gifts all the time after sexual intercourse [27]. A non-emotional partner was defined as a paying client towards whom the FSW felt no emotional attachment, or a rapist. Rape was defined as forceful non-consensual penile-vaginal sexual activity during the last 2 years. Data were collected on contraceptive use and consistent condom use with paying clients. Consistent condom use with paying clients was defined as using condoms all the time with men who paid for vaginal sex.

c) Social support and substance abuse

The FSWs were asked if they had someone to provide social support in case they wanted to get pregnant. Social support was defined as any support (emotional, informational, affectionate, tangible and positive social interaction) provided by trusted and reliable person [28]. The supporters were categorised as friend, relative, health provider and no supporter. Data were also collected on hazardous alcohol use based on "The Alcohol Use Disorders Identification Test" (AUDIT) Score $\geq 7$ [29]; and ever abuse of drugs.

\section{Data management and statistical analysis}

Completed questionnaires were stored in lockable cabinets with access to only authorised study staff. Double 
data entry was done using EpiData software. Data were then exported to STATA version 14.0 for analysis.

The socio-demographic characteristics of participants are described using frequencies with corresponding percentages or as medians with corresponding inter quartile ranges (IQR), or as means with corresponding standard deviations, as appropriate. By using principal component analysis, five wealth quintiles were built from household properties as a measure of socio-economic status.

Because the LMUP scores exhibited a bi-modal distribution (see Fig. 1), scores were grouped into three categories, with scores from 0 to 3 categorized as "unplanned" pregnancy, scores from 4 to 9 categorized as "ambivalent" pregnancy planning, and scores from 10 to 12 categorized as "planned" pregnancy. This categorization is consistent with published advice on use of the LMUP tool $[20,30]$. The prevalence of pregnancy planning was calculated as the percentage in each of the three categories. Statistical analyses included the chi-square test or Fisher's exact test, to assess the statistical significance of the association between the different categories of pregnancy planning and each of the independent variables. Additionally, for purposes of comparison with previous studies that considered pregnancy planning as a binary outcome [31], FSWs with LMUP scores less than 10 (including both unplanned and ambivalent) were considered as "unplanned pregnancy category".

Potential predictor variables investigated included those identified from the literature that have been found to be associated with pregnancy planning $[13,32]$. The multinomial logistic regression model was used to estimate the variations in the probability of planning for a pregnancy across the categories. The model assumes independence among the dependent variable choices [33]. The dependent variable was "pregnancy planning status" with three categories including unplanned (0-3), ambivalent

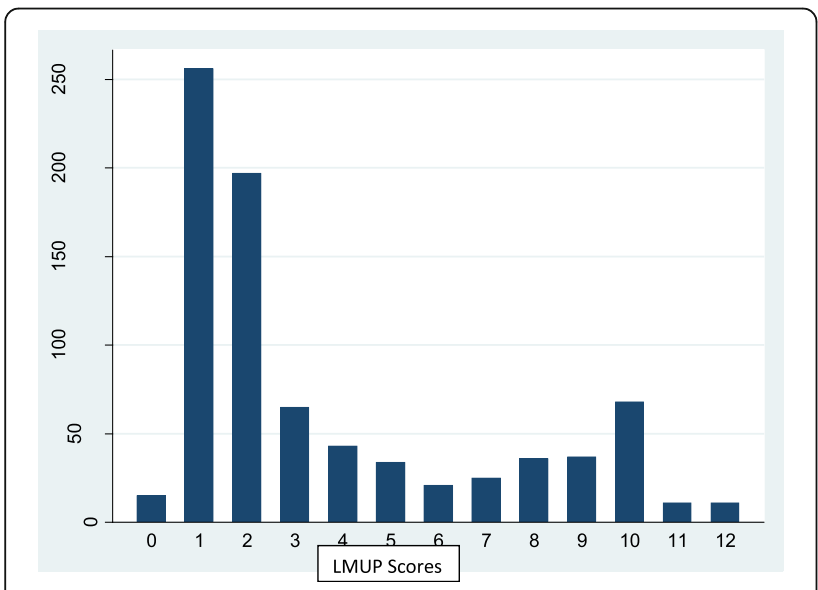

Fig. 1 Distribution of LMUP scores among female sex workers attending MARPI Clinics
(4-9), and planned (10-12). Then, we estimated the relative risk ratios with corresponding 95\% confidence intervals $(95 \% \mathrm{CI})$ for all independent variables per category of the dependent variable with exception of unplanned pregnancy which was considers as reference category. As a first step, all variables were included in the model, and then manual stepwise backward elimination was used to remove variables not significantly associated with pregnancy planning. Variables were removed one at a time, starting with those with the largest $p$-value, until only variables significantly associated with the outcome were left in the model. A $5 \%$ level of statistical significance $(\alpha=0.05)$ was used to retain variables significantly associated with pregnancy planning. Further, we investigated if any of the variables removed from the model confounded the relationship between any of the variables significantly associated with the outcome by checking if putting back such variables in the model changed the odds ratio of any of the variables retained in the model by at least $10 \%$. If putting back any variable in the model changed the relative risk ratio by at least $10 \%$, the variable was retained in the model regardless of its strength of association with the outcome variable. Each variable was investigated for confounding one by one.

\section{Results \\ Number of participants}

Overall a total of 925 FSWs attending MARPI clinics were screened for this study, out of which 106 (11.5\%) were ineligible. Among the ineligible, 3 were beyond 49 years, 99 reported no pregnancy within past 2 years, 40 had no sex for money or gifts, and 37 were intoxicated with either alcohol or drugs and could not consent even after resting for some hours (there were multiple reasons why some women were ineligible). The remaining 819 (88.5\%) eligible FSWs were enrolled, interviewed, and included in the analysis for this study.

\section{Characteristics of participants}

The overall median age of the FSWs interviewed was 27 years (IQR 23-30), ranging from 15 to 47 years. Of all participants, $448(54.7 \%)$ had attained primary education and $272(33.2 \%)$ had other sources of income besides sex work. Only 116 (14\%) FSWs reported were married or in union, while 480 (58.6\%) reported having an emotional partner as the man who fathered the most recent pregnancy before the study. There were 243 (29.7\%) HIV positive FSWs and $172(21 \%)$ FSWs were raped in past 2 years. Hazardous alcohol users were 462 (56.5\%) while 335 (40.9\%) reported drug abuse. The other characteristics of the participants are summarized in Table 1. 
Table 1 A summary of selected characteristics of the female sex workers enrolled in the study

\begin{tabular}{|c|c|c|c|}
\hline Characteristics $(N=819)$ & Categories & $\begin{array}{l}\text { Frequency } \\
\text { (n) }\end{array}$ & Percentage (\%) \\
\hline \multicolumn{4}{|l|}{ Socio and economic } \\
\hline \multirow[t]{3}{*}{ Age group } & $15-19$ yrs & 42 & 5.1 \\
\hline & $20-29$ yrs & 465 & 56.8 \\
\hline & $>30 \mathrm{yrs}$ & 312 & 38.1 \\
\hline \multirow[t]{3}{*}{ Education } & No education & 42 & 5.0 \\
\hline & Attended Primary (1-7 years) of education) & 448 & 54.7 \\
\hline & Attended Secondary or higher (at least 8 years of education) & 329 & 40.2 \\
\hline \multirow[t]{3}{*}{ Marital status } & Never married & 221 & 27.0 \\
\hline & Married or in union & 116 & 14.2 \\
\hline & Divorce/separated /widow & 482 & 58.8 \\
\hline \multirow[t]{5}{*}{ Wealth quintile } & Lowest & 178 & 21.7 \\
\hline & Second & 188 & 23.0 \\
\hline & Middle & 135 & 16.5 \\
\hline & Fourth & 196 & 23.9 \\
\hline & Highest & 122 & 14.9 \\
\hline Other source of income & Yes & 272 & 33.2 \\
\hline \multicolumn{4}{|l|}{ Sexual and obstetric history } \\
\hline \multirow[t]{3}{*}{ HIV status } & Positive & 243 & 29.7 \\
\hline & Negative & 563 & 68.7 \\
\hline & Not sure/unverified by record & 13 & 1.6 \\
\hline \multirow[t]{3}{*}{ Years in sex work } & $<2$ years & 249 & 30.4 \\
\hline & $3-5$ years & 313 & 38.2 \\
\hline & $>6$ years & 257 & 31.4 \\
\hline \multirow[t]{4}{*}{ Main workplace } & Street based & 270 & 33.0 \\
\hline & Entertainment place & 226 & 27.6 \\
\hline & Residence/homed based & 41 & 5.0 \\
\hline & Phone based & 282 & 34.4 \\
\hline \multirow[t]{2}{*}{ Partner for last pregnancy } & Emotional partner & 480 & 58.6 \\
\hline & Non Emotional partner & 339 & 41.4 \\
\hline \multirow[t]{3}{*}{ Number of living Children } & No Child & 380 & 46.4 \\
\hline & 1-3 children & 357 & 43.6 \\
\hline & Four and more Children & 82 & 10.0 \\
\hline Ever been raped in the last two years & Yes & 172 & 21.0 \\
\hline \multicolumn{4}{|l|}{ Having a supporter \& substance abuse } \\
\hline \multirow{4}{*}{$\begin{array}{l}\text { Reported having people to provide social support } \\
\text { if they wanted to get pregnant }\end{array}$} & Friend & 234 & 28.6 \\
\hline & Family member & 180 & 22.0 \\
\hline & Health worker & 172 & 21.0 \\
\hline & No support & 233 & 28.4 \\
\hline Hazardous alcohol user & Yes & 462 & 56.4 \\
\hline Substance use & Yes & 335 & 40.9 \\
\hline
\end{tabular}

\section{Contraceptive methods and condom use}

Overall, 803 (98.0\%) of the participants ever used any contraceptives and $698(85.3 \%)$ were current users. The male condom was the most common method among users $746(91.0 \%)$, though consistent condom use with paying client in the last month was lower at 594 (72.5\%). 
Use of natural methods was reported by $200(24.4 \%)$ while 475 (58.0\%) used dual contraception. Though, 556 (67.9\%) had heard about emergency contraceptives, only $40.6 \%$ of the 172 who were raped, accessed emergency contraception (Table 2).

\section{Levels of pregnancy planning}

Of the 819 FSWs, 90 (11\%) had planned for pregnancy (LMUP scores 10-12), 196 (23.9\%) were ambivalent (LMUP score 4-9), and 533 (65.1\%) did not plan the pregnancy (LMUP scores $0-3$ ). When pregnancy planning was considered as binary outcome, 729 (89\%) had unplanned pregnancies (0-9 scores). There was a fairly equal distribution of the proportion of FSWs who planned pregnancies, across wealth quintiles (except middle), and alcohol use categories. Other variables were not significant. The distribution of FSWs at different LMUP cut off points by selected independent variables is illustrated in Table 3.

\section{Predictors of pregnancy planning}

FSWs with a non-emotional partner as a man who impregnated her, were less likely to plan for a pregnancy by 0.15 times in the planned pregnancy category and 0.22 times in the ambivalent category, keeping other variables in the model constant. Similarly lack of social support reduced the level of pregnancy planning by 0.44 times among those in planned category and 0.54 times in the ambivalent category when other variables were held constant. Rape in the last 2 years and abusing substances significantly influenced planning of pregnancy among participants in the ambivalent group and not in the

Table 2 Knowledge and practices of contraceptive methods and condom use by FSWs attending MARPI clinics

\begin{tabular}{|c|c|c|}
\hline Characteristic $(N=819)$ & Frequency (n) & Percentage (\%) \\
\hline \multicolumn{3}{|l|}{ Ever used any method to delay pregnancy } \\
\hline Yes & 803 & 98.0 \\
\hline No & 16 & 2.0 \\
\hline \multicolumn{3}{|l|}{ Current users } \\
\hline Yes & 698 & 85.3 \\
\hline No & 76 & 9.3 \\
\hline Currently pregnant & 45 & 5.4 \\
\hline \multicolumn{3}{|l|}{ Current methods used ${ }^{a}$} \\
\hline Pill & 71 & 8.7 \\
\hline Injectable & 308 & 37.6 \\
\hline Implant & 109 & 13.3 \\
\hline Male condoms & 746 & 91.0 \\
\hline Female condoms & 149 & 18.2 \\
\hline Natural methods (lactation amenorrhea, rhythm and withdrawal) & 200 & 24.4 \\
\hline Emergency contraception & 25 & 3.1 \\
\hline \multicolumn{3}{|l|}{ Ever heard about emergency contraception } \\
\hline Yes & 556 & 67.9 \\
\hline No & 263 & 32.1 \\
\hline \multicolumn{3}{|l|}{ Ever used dual method (condom \& modern method) } \\
\hline Yes currently using & 475 & 58.0 \\
\hline Ever used but not currently using & 140 & 17.1 \\
\hline Never & 166 & 20.3 \\
\hline No answer & 38 & 4.6 \\
\hline \multicolumn{3}{|l|}{ Consistent condom use with paying client in last month } \\
\hline Yes & 594 & 72.5 \\
\hline No & 225 & 27.5 \\
\hline \multicolumn{3}{|l|}{ Condom use with last paying client } \\
\hline Yes & 748 & 92.5 \\
\hline No & 71 & 7.5 \\
\hline
\end{tabular}

${ }^{\mathrm{a}}$ Multiple responses were given 
Table 3 Planning status of pregnancy by selected characteristics of female sex workers

\begin{tabular}{|c|c|c|c|c|}
\hline Characteristics $(N=819)$ & $\begin{array}{l}\text { Unplanned } \\
N=533 \\
\mathrm{n}(\%)\end{array}$ & $\begin{array}{l}\text { Ambivalent } \\
N=196 \\
\mathrm{n}(\%)\end{array}$ & $\begin{array}{l}\text { Planned } \\
N=90 \\
n(\%)\end{array}$ & $\begin{array}{l}P \text { value } \\
\text { Chi2 } \\
\left(x^{2} \text { test }\right)\end{array}$ \\
\hline \multicolumn{4}{|l|}{ Age group } & \multirow[t]{4}{*}{$P=0.024^{*}$} \\
\hline $15-19 y r s$ & $21(3.9)$ & $15(7.6)$ & $6(6.7)$ & \\
\hline $20-29 y r s$ & $291(54.6)$ & $115(58.7)$ & $59(65.5)$ & \\
\hline$>30 y r s$ & $221(44.5)$ & $66(33.7)$ & $25(27.8)$ & \\
\hline \multicolumn{4}{|l|}{ Marital status } & \multirow[t]{4}{*}{$P=0.230$} \\
\hline Never married & $145(27.2)$ & $50(25.5)$ & $26(28.9)$ & \\
\hline Married or in union & $65(12.2)$ & $34(17.4)$ & $17(18.9)$ & \\
\hline Divorce/separated /widow & $32360.6)$ & $112(57.1)$ & $47(52.2)$ & \\
\hline \multicolumn{4}{|l|}{ Wealth quintile } & \multirow[t]{6}{*}{$P=0.016^{*}$} \\
\hline Lowest & $128(24.0)$ & $32(16.3)$ & $19(20.0)$ & \\
\hline Second & $129(24.2)$ & $38(19.4)$ & $21(23.3)$ & \\
\hline Middle & $88(16.5)$ & $38(19.4)$ & $9(10.0)$ & \\
\hline Fourth & $125(23.5)$ & $49(25.0)$ & $22(24.5)$ & \\
\hline Highest & $63(11.8)$ & 39 (19.9) & $20(22.2)$ & \\
\hline \multicolumn{4}{|l|}{ HIV status } & \multirow[t]{4}{*}{$P=0.618$} \\
\hline Positive & $160(30.0)$ & $62(31.6)$ & $21(23.3)$ & \\
\hline Negative & $364(68.3)$ & $132(67.4)$ & $67(74.5)$ & \\
\hline Not sure/unverified by records & $9(1.7)$ & $2(1.0)$ & $2(2.2)$ & \\
\hline \multicolumn{4}{|l|}{ Years in sex work } & \multirow[t]{4}{*}{$P=0.004^{*}$} \\
\hline$<2$ years & $141(26.4)$ & $73(37.2)$ & $35(38.9)$ & \\
\hline $3-5$ years & $204(38.3)$ & $74(37.8)$ & $35(38.9)$ & \\
\hline$>6$ years & $188(35.3)$ & $49(25.0)$ & $20(22.2)$ & \\
\hline \multicolumn{4}{|l|}{ Main workplace } & \multirow[t]{5}{*}{$P=0.218$} \\
\hline Street based & $174(32.7)$ & $65(33.2)$ & $31(34.4)$ & \\
\hline Entertainment place & $151(28.3)$ & $45(23.0)$ & $30(33.3)$ & \\
\hline Residence/homed based & $25(4.7)$ & $9(4.6)$ & $7(7.8)$ & \\
\hline Phone based & $183(34.3)$ & $77(39.3)$ & $22(24.4)$ & \\
\hline \multicolumn{4}{|l|}{ Partner for last pregnancy } & \multirow[t]{3}{*}{$P=0.000^{*}$} \\
\hline Emotional partner & $242(45.4)$ & $160(81.6)$ & $78(86.7)$ & \\
\hline Non emotional (Paying client/others) & $291(54.6)$ & $36(18.4)$ & $12(13.3)$ & \\
\hline \multicolumn{4}{|l|}{ Number of living Children } & \multirow[t]{4}{*}{$P=0.206$} \\
\hline No child & $249(46.7)$ & $91(46.4)$ & $40(44.4)$ & \\
\hline $1-3$ children & $222(41.7)$ & $90(45.9)$ & $45(50.0)$ & \\
\hline$\geq 4$ children & $62(11.6)$ & $15(7.65)$ & $15(5.6)$ & \\
\hline \multicolumn{4}{|l|}{ Ever been raped in last two years } & \multirow[t]{3}{*}{$P=0.000^{*}$} \\
\hline$-\mathrm{No}$ & $398(74.7)$ & $171(87.2)$ & $78(86.7)$ & \\
\hline -Yes & $135(25.3)$ & $25(12.8)$ & $12(13.3)$ & \\
\hline \multicolumn{4}{|c|}{ Reported having person/s to provide social support } & \multirow[t]{5}{*}{$P=0.000^{*}$} \\
\hline Friend & $134(25.1)$ & $67(34.2)$ & $33(36.7)$ & \\
\hline Family member & 99 (18.6) & $53(27.0)$ & $28(31.1)$ & \\
\hline Health worker & $121(22.7)$ & 37 (18.9) & $14(15.5)$ & \\
\hline No support & 179 (33.6) & 39 (19.9) & $15(16.7)$ & \\
\hline
\end{tabular}


Table 3 Planning status of pregnancy by selected characteristics of female sex workers (Continued)

\begin{tabular}{|c|c|c|c|c|}
\hline Characteristics $(N=819)$ & $\begin{array}{l}\text { Unplanned } \\
N=533 \\
\mathrm{n}(\%)\end{array}$ & $\begin{array}{l}\text { Ambivalent } \\
N=196 \\
\mathrm{n}(\%)\end{array}$ & $\begin{array}{l}\text { Planned } \\
N=90 \\
n(\%)\end{array}$ & $\begin{array}{l}P \text { value } \\
\text { Chi2 } \\
\left(x^{2} \text { test }\right)\end{array}$ \\
\hline Alcohol use & & & & $P=0.025^{*}$ \\
\hline Non-Hazardous drinking & $214(40.2)$ & $97(49.5)$ & $46(51.1)$ & \\
\hline Hazardous drinking & $319(59.8)$ & $99(50.5)$ & $44(48.9)$ & \\
\hline Substance use & & & & $P=0.002^{*}$ \\
\hline No & $291(54.6)$ & $132(67.3)$ & $61(67.8)$ & \\
\hline Yes & $242(45.4)$ & $64(32.7)$ & $29(32.2)$ & \\
\hline
\end{tabular}

*Significant statistical difference between groups, Pearson`s Chi-square or Fisher`s test $(P<0.05)$

planned category. Holding other variables constant, the risk of being in ambivalent group versus unplanned group was 0.51 times less for participants who had ever been raped in the last 2 years relative to those who reported being never raped. Lastly the FSWs who ever abused substances were 0.65 times less likely to plan for pregnancy in the ambivalent category compared to those who did not abuse substances keeping all variables in the model constant. All variables that were significant in the final model are shown in Table 4.

\section{Discussion}

Our study shows a low prevalence $(11.0 \%)$ of planned pregnancies among FSWs in Uganda. This is comparatively lower than the $44 \%$ which was reported in another study in northern Uganda [15] and the 59\% among women in the general population [23]. The observed low prevalence could be because of more nuanced measurement using the LMUP tool. We were able to categorise pregnancy planning into three groups, rather than two. This included ambivalent status which allows women to express their indecisiveness about pregnancy planning. Indeed, a substantial percentage of the participants (23.9\%) in this study were ambivalent about pregnancy planning. Previous studies have categorised planning status into binary outcome of planned and unplanned pregnancy which assumes that women have clarity on whether to get pregnant or not before conception.

The overall low proportions of FSWs with planned pregnancies could be attributed to poor utilization of reliable family planning methods. In this study though about $85 \%$ of the FSWs reported to be currently using a method to delay pregnancy, many used methods with high failure rates. We observed high proportions (91.0\%) reporting condom use but consistent use was $72 \%$. Inconsistent condom use is less effective as a pregnancy prevention tool and may have predisposed FSWs to unplanned pregnancies [34]. Others reported using

Table 4 Multinomial logistic regression analysis showing factors associated with pregnancy planning

\begin{tabular}{|c|c|c|c|c|}
\hline \multirow[t]{2}{*}{ Variables/categories } & \multicolumn{2}{|c|}{ Planned Pregnancies } & \multicolumn{2}{|c|}{ Ambivalent Pregnancies } \\
\hline & RRR & $95 \% \mathrm{Cl}$ & RRR & $95 \% \mathrm{Cl}$ \\
\hline \multicolumn{5}{|l|}{ Partner for last pregnancy } \\
\hline Emotional partner (rc) & 1.00 & - & 1.00 & - \\
\hline Non emotional (Paying client/others) & *0.16 & $(0.08-0.30)$ & ${ }^{*} 0.22$ & $(0.15-0.33)$ \\
\hline \multicolumn{5}{|c|}{ Reported having person/s to provide social support } \\
\hline Friend $(\mathrm{rc})$ & 1.00 & - & 1.00 & - \\
\hline Family member & 1.08 & $(0.60-1.95)$ & 1.01 & $(0.62-1.61)$ \\
\hline Health worker & 0.54 & $(0.27-1.09)$ & 0.68 & $(0.42-1.13)$ \\
\hline No support & ${ }^{*} 0.44$ & $(0.22-0.87)$ & ${ }^{*} 0.54$ & $(0.33-0.88)$ \\
\hline \multicolumn{5}{|l|}{ Ever been raped in last two years } \\
\hline No (rc) & 1.00 & - & 1.00 & - \\
\hline Yes & 0.55 & $(0.28-1.07)$ & ${ }^{*} 0.51$ & $(0.31-0.84)$ \\
\hline \multicolumn{5}{|l|}{ Substance use } \\
\hline No (rc) & 1.00 & - & 1.00 & - \\
\hline Yes & 0.63 & $(0.38-1.04)$ & ${ }^{*} 0.61$ & $(0.44-0.93)$ \\
\hline
\end{tabular}

Note: rc Reference category, $L R$ chi square 150.68 , Pseudo $R^{2} 10.6 \%$, base model Unplanned pregnancy; *means variable is significant at $p<0.05$ 
natural methods, and dual use of contraceptives was at only $58 \%$. A previous study in Uganda [15] and other countries in Africa [35] indicated low dual contraceptive use, even among FSWs with no intention of getting pregnant. Dual contraception with a condom and other effective contraceptive would be ideal for this population which is at high risk of pregnancy and other sexually transmitted infections including HIV [15] .

We observed that FSWs who had been raped within the previous 2 years were less likely to have planned their most recent pregnancy. We also observed that only $40 \%$ of the women who were raped accessed emergency contraception (EC). Failure to use EC after unprotected sex leads to unplanned pregnancies among FSWs not using modern contraceptives. Similarly, a cross-sectional survey conducted in Gambia in 2015, found high levels of unplanned pregnancies among FSWs who had experienced sexual violence [36].

In this study, no association was observed with alcohol and pregnancy planning in the adjusted analysis. However, an association between drug use and reduced pregnancy planning was found. This could be linked to failure to negotiate for condom use with clients after getting intoxicated with drugs as was noted in other low income countries [37]. Similarly, the Gambia study found that alcohol had no effect on the ability to negotiate for condom use among FSWs with patrons. There is no clear explanation as to why alcohol use had no effect yet drug use reduced the odds of pregnancy planning in either this or our study. However, in this study we excluded FSWs who were intoxicated with alcohol and other substances at screening, which could potentially contribute to this finding. A qualitative study among a cohort of FSWs in Uganda indicated that clients usually take advantage of drunken FSWs to have unprotected sex [38]. Since there are many participants who reported to be using drugs or taking alcohol in this study there is need to intensify intervention for harm reduction.

Low levels of pregnancy planning were observed among FSWs who had non-emotional partner as the man who fathered the last pregnancy. Most of the non-emotional partners were paying clients. This could be attributed to failure to use condoms consistently and correctly as a result of rushing negotiations with non-emotional partners among FSWs given that sex work is illegal and attracts penalties [9, 39]. A study conducted among FSWs in Gulu in northern Uganda found that rushing negotiation with clients due to police presence was negatively associated with dual contraceptive use [15]. Inadequate time to negotiate condom use and low utilization of modern contraception leads to unplanned pregnancies.

Again we observed low levels of pregnancy planning among participants who had no person to provide social support. A study among a cohort of family planning clients in Kenya showed that women receiving health services from providers offering high levels of quality of care are more likely to plan for pregnancies [40]. However, in this study we did not assess the quality of care at the MARPI clinics. Social support shapes pregnancy experiences among women especially in low income countries with high rates of unintended pregnancy [41]. Women who receive appropriate social support are likely to have reduced rates of induced abortions [42]. However, further studies are needed to better understand the actual support provided by different individuals in order to devise interventions to reduce induced abortions among FSWs.

No significant association was observed between planned pregnancies and HIV status. Though HIV status was self-reported and cross checked with records, we observed a higher HIV prevalence of $29.7 \%$ among the FSWs in this study compared to $7.6 \%$ among women in the general population [43]. A study conducted in study in Abidjan, Côte d'Ivoire in 2015 found no significant difference in the proportion of unplanned pregnancies among HIV infected and uninfected FSWs [12]. Due to regular contact with health facilities as women seek HIV treatment and care, one would expect HIV infected FSWs to plan better for pregnancies. However this may be limited by the generally low integration of safer conception support in HIV care [44]. More interventions are required to control the acquisition and spread HIV among FSWs in Uganda as well as focusing on pregnancy planning.

\section{Strengths and limitations}

This is the first study to our knowledge that has assessed pregnancy planning among FSWs using the LMUP tool. The use of LMUP instead of a one-question method is a strength, and this may have helped to reduce misclassification of unplanned pregnancies [13]. In addition, this paper draws strength from the systematic selection of participants at the MARPI clinics in the four regions of the country (Central, Eastern, Northern and Western). This implies that FSWs attending MARPI clinics had equal chances of being selected. We included pregnant, post-partum and FSWs who had had abortions, catering for all possible pregnancy outcomes. Though some literature has shown differing pregnancy intendedness after delivery [45] a longitudinal study conducted in India using the LMUP found no increase in reported pregnancy intention after 2 year of follow up [24]. This implies results can be applied to both pregnant and postpartum FSWs.

There are some limitations with our study. First our study is informed by reported behaviours. The FSWs may have inaccurately reported their sexual behaviours 
due to recall bias as FSWs recruited in the study could have been pregnant at any time over a two-year interval. Since most women in African settings are expected to have children, social desirability among FSWs could have contributed to over reporting of pregnancy planning. We believe our well-trained research assistants, supervised by the principle investigator who has worked with FSWs over 10 years, established strong rapport and trust among the FSWs to provide accurate information. Lastly we cannot interpret the temporal relationship between independent variables and pregnancy planning among FSWs because of the cross sectional study design used. Since the sample included in the study was clinic based, the findings may not be generalizable to all sex workers in Uganda.

\section{Conclusion and recommendation}

We found low prevalence of planned pregnancies among FSWs compared to women in the general population in Uganda amidst low and inconsistent contraceptive use. Our results emphasize the need to design robust approaches to implement comprehensive reproductive health services among FSWs. In particular, there is urgent need to promote consistent use of reliable contraceptives among FSWs to prevent unplanned pregnancies with non-emotional partners and after rape. While our study has identified the prevalence and predictors of pregnancy planning, there is need to conduct further research to assess the impact of pregnancy intention on pregnancy outcome and utilization of maternal services among FSWs.

\section{Abbreviations \\ AUDIT: The Alcohol Use Disorders Identification Test; EC: Emergency contraception; FSWs: Female Sex Workers; HIV: Human Immunodeficiency Virus; IQR: Inter-Quintile Range; LMUP: London Measure of Unplanned Pregnancy; MARPI: Most at Risk Population Initiative}

\section{Acknowledgements}

We are grateful to the staff and management of MARPI clinics where data were collected and the research assistants who diligently collected data. We thank the FSWs for accepting to participant in this study.

\section{Funding}

Data collection for this study was conducted as part of the Ministry of Health and Global Fund supported Sexual and Reproductive Health/Family Planning integration evaluation. The funding body was not involved in the design of the study, collection, analysis, interpretation of data, and in writing the manuscript.

\section{Availability of data and materials}

The datasets generated and/or analysed during the current study are not publicly available due to sensitivity and illegal nature of sex work in Uganda but are available from the corresponding author on reasonable request.

\section{Authors' contributions}

JNB conceptualized the study and wrote the study proposal, participated in data collection, data analysis and wrote the first draft of the manuscript. RW participated in conceptualized the study and writing the study proposal and the manuscript. GB contributed to proposal writing, data analysis and writing of the manuscript. JH and FM contributed to data analysis, and writing of the manuscript. DG contributed to conceptualization of the study and writing the study proposal, data analysis and writing of manuscript. All authors approved the final copy of the manuscript before submission.

\section{Ethics approval and consent to participate}

The study was approved by Makerere University School of Public Health Higher Degrees, Research and Ethics Committee and the Uganda National Council for Science and Technology (No: SS 4262). Permission to conduct the study was further sought from the MARPI Clinic managers and written informed consent was obtained from participants. Adolescents below age of 18 years were considered as emancipated minors and independently provided informed consent to participate in research as specified in the national guidelines [46]. Interviews were conducted in secluded locations within or outside facility premises to ensure client's confidentiality. To ensure confidentiality of the data collected, no names were recorded on the data collection tool. Names were only recorded on consent forms, which were filed separately.

\section{Consent for publication}

Not applicable.

\section{Competing interests}

The authors declare that they have no competing interests.

\section{Publisher's Note}

Springer Nature remains neutral with regard to jurisdictional claims in published maps and institutional affiliations.

\section{Author details}

${ }^{1}$ School of Public Health, College of Health Sciences Makerere University, P.O. Box 7072, Kampala, Uganda. Institute for Women's Health, University College London, London, UK.

Received: 1 June 2018 Accepted: 25 March 2019

Published online: 08 April 2019

\section{References}

1. Stephenson J, et al. Before the beginning: nutrition and lifestyle in the preconception period and its importance for future health. Lancet. 2018; 391(10132):1830-41.

2. Hall JA, et al. Pregnancy intention and pregnancy outcome: systematic review and meta-analysis. Matern Child Health J. 2017;21(3):670-704.

3. Gipson JD, Koenig MA, Hindin MJ. The effects of unintended pregnancy on infant, child, and parental health: a review of the literature. Stud Fam Plan. 2008:39(1):18-38.

4. Tsui AO, McDonald-Mosley R, Burke AE. Family planning and the burden of unintended pregnancies. Epidemiol Rev. 2010:32:152-74.

5. Vlassoff $\mathrm{M}$, et al. The health system cost of post-abortion care in Uganda. Health Policy Plan. 2014;29(1):56-66.

6. World Health Organization. Policy Brief on preconception care: Maximizing the gains for maternal and child health, 2013. Geneva: Department of Maternal, Newborn, Child and Adolescent Health, World Health Organization; 2013.

7. Vandepitte J, et al. Estimates of the number of female sex workers in different regions of the world. Sex Transm Infect. 2006;82(Suppl 3):iii18-25.

8. Crane Survery Report. High Risk Group Surveys Conducted in 2008/9. Kampala: Makerere University, PEPFAR, United States Centers for Disease Control and Prevention, and Republic of Uganda Ministry of Health; 2010.

9. Uganda: The Penal Code Act (Cap. 120), 1950 [Uganda], 15 June 1950. Available at: https://www.refworld.org/docid/59ca2bf44.html. Accessed 2 Apr 2018

10. Vandepitte J, et al. HIV and other sexually transmitted infections in a cohort of women involved in high-risk sexual behavior in Kampala, Uganda. Sex Transm Dis. 2011;38(4):316-23. https://doi.org/10.1097/OLQ. Ob013e3182099545.

11. Weldegebreal R, et al. Unintended pregnancy among female sex workers in Mekelle city, northern Ethiopia: a cross-sectional study. BMC Public Health. 2015;15:40.

12. Schwartz $\mathrm{S}$, et al. An urgent need for integration of family planning services into HIV care: the high burden of unplanned pregnancy, termination of 
pregnancy, and limited contraception use among female sex workers in cote d'Ivoire. J Acquir Immune Defic Syndr. 2015;68(Suppl 2):S91-8.

13. Hall J, et al. Understanding pregnancy planning in a low-income country setting: validation of the London measure of unplanned pregnancy in Malawi. BMC Pregnancy and Childbirth. 2013;13(1):200.

14. Loutfy M, et al. Fertility desires and intentions of HIV-positive women of reproductive age in Ontan Canada: a cross sectional study. PLoS One. 2009; 4(12):e7925.

15. Erickson $M$, et al. Structural determinants of dual contraceptive use among female sex workers in Gulu, northern Uganda. Int J Gynaecol Obstet. 2015 131(1):91-5.

16. Bukenya J, et al. Condom use among female sex workers in Uganda. AIDS Care. 2013;25(6):767-74.

17. Uganda AIDS Commission. The MARPS Priority Action Plan 2015-2018. Kampala: Uganda AIDS Commission; 2015

18. Barrett $G$, Wellings $K$. Understanding pregnancy intentions: a problem in evidence everywhere. Fam Plan Perspect. 2000;32(4):194.

19. Barrett $G$, Wellings K. What is a 'planned' pregnancy? Empirical data from a British study. Soc Sci Med. 2002;55:545-57.

20. Barrett G, Smith S, Wellings K. Conceptualisation, development and evaluation of a measure of unplanned pregnancy. J Epidemiol Community Health. 2004;58(5):426-33.

21. Most At Risk Populations Initiative, Annaul Report of Most At Risk Populations Initiative Programe 2014, National STD Control Unit, Ministry of Health: Kampala, Uganda.

22. Israel GD. Determining Sample Size. University of Florida Cooperative Extension Service, Institute of Food and Agriculture Sciences, EDIS, Florida; 1992. Available at https://www.tarleton.edu/academicassessment/ documents/Samplesize.pdf. Accessed 4 May 2018.

23. Uganda Bureau of StatistCs (UBOS) and ICF. Uganda Demographic and Health Survey 2016. Maryland: UBOS and ICF: Uganda and Rockville; 2018.

24. Rocca $\mathrm{CH}$, et al. Measuring pregnancy planning: an assessment of the London measure of unplanned pregnancy among urban, South Indian women. Demogr Res. 2010;23:293-334.

25. Roshanaei $\mathrm{S}$, et al. Measuring unintended pregnancies in postpartum Iranian women: validation of the London measure of unplanned pregnancy. East Mediterr Health J. 2015;21(8):572-8.

26. Morof $D$, et al. Evaluation of the London measure of unplanned pregnancy in a United States population of women. PLoS One. 2012;7:e35381.

27. Luchters $\mathrm{S}$, et al. The contribution of emotional partners to sexual risk taking and violence among female sex workers in Mombasa, Kenya: a cohort study. PLoS One. 2013;8(8):e68855.

28. Kim TH, Connolly JA, Tamim H. The effect of social support around pregnancy on postpartum depression among Canadian teen mothers and adult mothers in the maternity experiences survey. BMC Pregnancy Childbirth. 2014;14:162.

29. Lancaster KE, et al. Socioecological factors related to hazardous alcohol use among female sex Workers in Lilongwe, Malawi: a mixed methods study. Subst Use Misuse. 2018:53(5):782-91.

30. Hall JA, et al. London measure of unplanned pregnancy: guidance for its use as an outcome measure. Patient Relat Outcome Meas. 2017;8: 43-56.

31. Habib MA, et al. Prevalence and determinants of unintended pregnancies amongst women attending antenatal clinics in Pakistan. BMC Pregnancy Childbirth. 2017;17(1):156.

32. Uganda Bureau of Statistics and ICF International Inc. Uganda Demographic and Health Survey 2011. Kampala: UBOS and Calverton, Maryland: ICF International Inc; 2012.

33. Hosmer DW, Lemeshow S. Applied logistic regression. 2nd ed. New York: Wiley; 2000

34. Ippoliti NB, Nanda G, Wilcher R. Meeting the reproductive health needs of female key populations affected by HIV in low- and middle-income countries: a review of the evidence. Stud Fam Plan. 2017;48(2):121-51.

35. Chanda MM, et al. Contraceptive use and unplanned pregnancy among female sex workers in Zambia (0)(). Contraception. 2017;96(3):196-202.

36. Sherwood JA, et al. Sexual violence against female sex workers in the Gambia: a cross-sectional examination of the associations between victimization and reproductive, sexual and mental health. BMC Public Health. 2015;15(1):270.

37. Urada LA, et al. Condom negotiations among female sex Workers in the Philippines: environmental influences. PLoS One. 2012;7(3):e33282.
38. Mbonye $\mathrm{M}$, et al. It is like a tomato stall where someone can pick what he likes': structure and practices of female sex work in Kampala, Uganda. BMC Public Health. 2013;13(1):741

39. Scorgie $F$, et al. Human rights abuses and collective resilience among sex workers in four African countries: a qualitative study. Glob Health. 2013;9(1):33.

40. Wekesa E, Askew I, Abuya T. Ambivalence in pregnancy intentions: the effect of quality of care and context among a cohort of women attending family planning clinics in Kenya. PLoS One. 2018;13(1):e0190473.

41. Lewinsohn $\mathrm{R}$, et al. This baby came up and then he said, "I give up!": The interplay between unintended pregnancy, sexual partnership dynamics and social support and the impact on women's well-being in KwaZulu-Natal, South Africa. Midwifery. 2018;62:29-35.

42. Sánchez-Siancas LE, et al. Association between perceived social support and induced abortion: a study in maternal health centers in Lima, Peru. PLoS One. 2018;13(4):e0192764.

43. Ministry of Health. Uganda Population-Based HIV Impact Assessment (UPHIA) 2016-2017; Summary Sheet: Preliminary Findings. Kampala: Ministry of Health; 2017. p. 1-4

44. Mindry D, et al. Safer conception for couples affected by HIV: structural and cultural considerations in the delivery of safer conception Care in Uganda. AIDS Behav. 2017:21(8):2488-96.

45. Population Council. Population Council. Conceptualizing and Measuring Unintended Pregnancy and Birth: Moving the Field Forward. Accra: Population Council; 2015. p. 20

46. Uganda National Council for Science and Technology (UNCST). National Guidelines for Research involving Humans as Research Participants. Kampala: UNCST; 2014

\section{Ready to submit your research? Choose BMC and benefit from:}

- fast, convenient online submission

- thorough peer review by experienced researchers in your field

- rapid publication on acceptance

- support for research data, including large and complex data types

- gold Open Access which fosters wider collaboration and increased citations

- maximum visibility for your research: over $100 \mathrm{M}$ website views per year

At $\mathrm{BMC}$, research is always in progress.

Learn more biomedcentral.com/submissions 